\title{
Como fazer relatórios em Geociências
}

\author{
Fernanda Quaglio \\ Instituto de Geociências e Ciências Exatas, \\ Universidade Estadual Paulista (UNESP), Rio Claro \\ quaglio@gmail.com

\section{Carlos H. Grohmann} \\ Instituto de Energia e Ambiente, Divisão Científica de \\ Tecnologia de Petróleo, Gás Natural e Bioenergia. Av. \\ Prof. Luciano Gualberto, 1289, Cidade Universitária, \\ São Paulo \\ guano@usp.br \\ Thomas R. Fairchild \\ Instituto de Geociências, Universidade de São Paulo, \\ São Paulo \\ trfairch@hotmail.com
}

\begin{abstract}
HOW TO PREPARE UNDERGRADUATE TERM PAPERS IN GEOSCIENCES. Term papers are educational tools for students to present a topic related to a discipline in the form of an academic text. They are part of the natural learning process of the students. However, the student often encounters more difficulty in elaborating reports than in learning about the subject matter related to the discipline itself. Moreover, useful information for the elaboration of reports is commonly dispersed throughout the literature on the subject. The aim of this guide is to orient undergraduate students in Geosciences on how to present well-structured and well-presented term papers with high quality texts. Here we bring together step-by-step instructions on organizing and developing undergraduate term papers, including tips on library research, text presentation, citations, and preparation of tables, figures and references.
\end{abstract}

KEYWORDS Geosciences; Term paper; Undergraduate education; Academic text.

RESUMO Relatórios são recursos didáticos empregados para que os alunos apresentem, na forma de texto acadêmico, um tema relacionado à disciplina em curso. São, portanto, parte do processo natural de aprendizagem dos estudantes. Muitas vezes, no entanto, o aluno enfrenta maior dificuldade na elaboração do relatório em si do que na aprendizagem sobre o tópico da disciplina. Além disso, as informações úteis para a elaboração de relatórios de disciplina comumente se encontram dispersas na literatura geral sobre o tema. O objetivo principal deste guia é orientar o aluno de graduação em Geociências a desenvolver relatórios bem estruturados e apresentados, que abordem com textos de qualidade os tópicos relacionados à disciplina. Está aqui reunido o passo-a-passo para a organização e desenvolvimento de um relatório, incluindo dicas importantes para pesquisa bibliográfica, apresentação do texto, citações, formatação de tabelas, figuras e referências.

PALAVRAS-CHAVE Geociências; Relatório; Graduação; Texto acadêmico. 


\section{1 - Introdução}

Os relatórios são desenvolvidos com o objetivo de apresentar resultados de trabalhos de campo, análises de amostras, ou mesmo revisão bibliográfica sobre um tema específico abordado pelo programa de disciplinas de graduação. Como ferramenta didática aplicada pelos professores, diversos relatórios são apresentados pelos alunos ao longo de cursos de graduação em Geologia/Geociências. A confecção dos relatórios é parte natural do processo de aprendizagem dos estudantes. No entanto, é comum o aluno enfrentar maior dificuldade em aprender a confeccionar o relatório do que em assimilar os tópicos das disciplinas.

Embora não constituam artigos científicos e tampouco monografias, os relatórios oferecem a oportunidade para o aluno de graduação adquirir experiência com a redação científica. Os relatórios também representam oportunidade para experimentar as fases de execução necessárias na elaboração de artigos, seguindo as normas específicas de publicações científicas. Tais fases incluem o levantamento bibliográfico, análise de amostras, tratamento e interpretação dos dados, comparação com estudos prévios, discussão e conclusões, bem como a estruturação do trabalho e organização das figuras, tabelas e referências bibliográficas.

Assim, a experiência será importante não somente quando o aluno redigir sua monografia de trabalho de conclusão de curso, como também durante sua pós-graduação e carreira profissional.

\section{1 - Justificativas e objetivos}

Diversos trabalhos sobre confecção de trabalhos acadêmicos estão disponíveis para consulta. Entre os estrangeiros, Umberto Eco aborda os passos na elaboração de monografias e discorre elegantemente sobre a chamada "alquimia da tese" (Eco 1990, p. 24). Gustavii (2003) apresenta sugestões práticas de como redigir e ilustrar artigos científicos. Dentre os trabalhos desenvolvidos por autores brasileiros, Jost e Brod (2005) apresentam as principais características, elementos e erros mais comuns em textos acadêmicos em Geociências, com base em suas experiências como editores de revistas científicas e participações em bancas de pós-graduação. Já Oliveira e Sígolo (2005) destacam as regras para confecção de teses e dissertações de acordo com as normas da ABNT, com ênfase nos trabalhos acadêmicos desenvolvidos por estudantes de pós-graduação do IGc-USP. Severino (2007) discorre sobre o desenvolvimento do trabalho científico.

A despeito da diversidade de trabalhos sobre redação científica, são raros ou mesmo inexistentes textos voltados para a elaboração de relatórios de disciplinas de graduação em Geociências. O presente trabalho reúne orientações para suprir a lacuna.

\section{2 - Os relatórios em Geociências}

Basicamente dois tipos gerais de relatórios podem ser solicitados em disciplinas de Geologia/ Geociências: os de revisão bibliográfica e os que incluem trabalho de campo com ou sem coleta de material para posterior análise em laboratório.

A estrutura geral e cada capítulo ou subdivisão do trabalho dependerão da natureza do relatório, embasada em seus objetivos principais. Assim, é importante compreender profundamente os objetivos, o que auxilia a manter o foco e a unidade do trabalho sem despender de muito tempo para finalizá-lo.

Os relatórios de revisão bibliográfica geralmente abordam uma unidade geológica com um tema específico: conteúdo fóssil em relação a um ou mais grupos taxonômicos, amostras litológicas, emprego de diferentes métodos analíticos, ou mesmo histórico das pesquisas realizadas sobre aquela unidade ou região. Ainda que seja apenas de revisão bibliográfica, este tipo de relatório pode apresentar análise estatística, ou mesmo organização de dados levantados em gráficos de histograma, pizza, dispersão etc. Nesses casos, devem conter a seção de métodos.

Os relatórios com base em trabalhos de campo, como os de mapeamento, dependem de dois tipos de coleta: de dados e de material. A coleta de dados se refere às informações e observações obtidas durante o campo e que são anotadas na caderneta e registradas em imagens fotográficas. Como a caderneta é a principal fonte de dados para a descrição dos resultados, é de extrema importância anotar todas as informações e detalhes observados no campo, incluindo croquis, desenhos e esquemas, além de possíveis interpretações e dúvidas. Todas as informações devem estar bem organizadas, para que nenhum dado seja perdido durante a descrição, análise e discussão dos resultados. A fase de documentação fotográfica durante o campo é igualmente fundamental para registrar as características litológicas, afloramentos e feições fisiográficas. As imagens obtidas durante o campo são de grande valia para auxiliar a memória, e como complementação às informações armazenadas na caderneta, pois registram fielmente detalhes que podem 
passar despercebidos no campo, como estruturas, texturas, cores, graus de alteração, dimensões de afloramentos e diversas outras características (A. Bartorelli 2014, comunicação verbal).

A coleta de material constitui a amostragem de frações de rocha para posterior estudo em laboratório. As informações de coleta, as quais devem ser anotadas na caderneta, incluem características gerais do afloramento, litologia, coordenadas, nível estratigráfico, etc. Sem essas informações, a amostra perde totalmente seu valor científico.

Em alguns relatórios de mapeamento, as amostras coletadas deverão ser encaminhadas à laminação para posterior análise petrográfica. As descrições petrográficas são importantes para acessar detalhes sobre as diferentes litologias encontradas e que acrescentarão informações importantes ao mapa final. Nesses casos, é importante adicionar ao trabalho as descrições petrográficas como um dos apêndices.

Alguns mapas e croquis, que representam fases prévias à elaboração do mapa final, também podem ser solicitados como apêndices. O mapa de pontos deve conter a localização dos dados encontrados, incluindo informações litológicas e controle estrutural, isto é, as medidas estruturais levantadas no local amostrado. No caso de relatórios de mapeamento sedimentar, é importante que sejam apresentados mapas indicando os afloramentos descritos e caminhamento, ou seja, o traçado percorrido com indicação dos contatos entre cada unidade encontrada. Com isso, o professor poderá avaliar como os alunos realizaram a amostragem e confeccionaram o mapa final.

\section{3 - Estrutura de apresentação}

A estrutura de um trabalho determina a fluidez com a qual o leitor compreenderá o assunto abordado. Assim, um resumo deve ser a primeira seção apresentada, pois é a partir daí que o leitor se informa das linhas gerais e conclusões do trabalho, e também decide ler ou não o restante do trabalho. Como o próprio nome sugere, o resumo sintetiza tema, objetivos, área de estudo, abordagem adotada e conclusões.

A introdução apresenta o tema de forma generalizada, com ênfase no contexto e a problemática científica do trabalho. Após introduzir o leitor ao assunto geral, são listados os objetivos.

A geologia regional vem em seguida, descrevendo o arcabouço geológico. Depois, os materiais e métodos detalham o objeto de estudo, bem como as técnicas utilizadas para a obtenção dos dados.

A seguir, devem ser apresentados os resultados e discussões a respeito do trabalho.

As conclusões devem encerrar o relatório, arrematando os objetivos apresentados inicialmente.

As referências bibliográficas devem ser listadas após o texto, para possibilitar ao leitor a busca das fontes citadas.

O relatório pode ainda conter documentos anexos, como listas extensas de dados, tabela ou mapa de pontos, fichas descritivas ou mesmo perfil geológico, figuras ou mapas que tenham que ser consultados continuamente em todas as seções do trabalho. Quando construídos pelo autor do texto, tais documentos constituem apêndices. Se utilizados a partir de outros trabalhos, são chamados de anexos (ABNT 1989). Os apêndices e anexos sempre devem ser apresentados por último, pois representam documentos suplementares ao texto principal.

\section{4 - Elaboraçãa}

A ordem de apresentação das seções de um relatório - ou seja, sua estrutura - não é a mesma daquela usada para a execução do trabalho (Fig. 1).

\begin{tabular}{|c|c|c|}
\hline \multicolumn{2}{|c|}{ ORDEM DE DESENVOLVIMENTO DO TRABALHO } & ORDEM DE AP \\
\hline PRÉ-REDAÇÃO & $\begin{array}{r}\text { Definição do Tema e Objetivos } \\
\text { Estruturação/ Índice } \\
\text { Seleção de Referências }\end{array}$ & $\begin{array}{l}\text { Capa } \\
\text { Índice }\end{array}$ \\
\hline REDAÇÃO & $\underline{\text { Resultados e e }} \begin{array}{r}\begin{array}{r}\text { Geologia Regional } \\
\text { Material e Métodos da Discussão }\end{array} \\
\underline{\text { Introdução }}\end{array}$ & $\begin{array}{c}\text { Resumo } \\
\text { Introdução } \\
\text { Objetivos } \\
\text { Geologia Regional }\end{array}$ \\
\hline FINALIZAÇÃO & $\begin{array}{r}\text { Finalização da Discussão } \\
\frac{\text { Conclusões }}{\text { Complementação dos } \frac{\text { Objetivos }}{\text { Resumo }}} \\
\text { Verificação final } \\
\text { (incluindo Referências, Anexos e Capa) }\end{array}$ & $\begin{array}{c}\text { Material e Métodos } \\
\text { Resultados } \\
\text { Discussão } \\
\text { Conclusões } \\
\text { Referências bibliográficas } \\
\text { Anexos }\end{array}$ \\
\hline
\end{tabular}

Figura 1. Ordem de desenvolvimento do trabalho, com as etapas de préredação, redação e finalização, e ordem de apresentação no documento final. 
É equivocado tentar executar o trabalho na mesma ordem da apresentação das seções no documento final. Isto comumente compromete a concatenação de ideias e argumentos, bem como a fluidez da leitura.

O professor Gilberto Amaral (IGc-USP e Unicamp), em um manuscrito não publicado sobre a elaboração de teses em Geociências, sugere que o desenvolvimento da pesquisa científica deve utilizar a "abordagem sistêmica" (G. Amaral, sem data, Como fazer uma tese em Geociências?, Manuscrito inédito, $57 \mathrm{p}$.). Esta abordagem implica o planejamento das várias etapas de execução, como definição do tema de estudo, seleção bibliográfica, coleta de dados, interpretação, conclusões etc. A última etapa corresponde à fase de avaliação, quando se verifica se os objetivos de cada etapa do projeto foram contemplados. Caso não tenham sido atingidos, deve-se realimentar o sistema, isto é, refazer os passos de certas etapas, mas não necessariamente todo o trabalho.

Em qualquer trabalho acadêmico, incluindo os relatórios de disciplinas, deve-se adotar a abordagem sistêmica, realizando-se cada fase aos poucos, avaliando-se se os objetivos foram atingidos e executando-se novamente a fase necessária. Dessa forma, o trabalho é aperfeiçoado aos poucos e ganha maior unidade e robustez. Este método produz resultados melhores e em menos tempo do que a abordagem unidirecional, na qual cada etapa do estudo é realizada de uma única vez.

\section{1 - Pré-redação: por onde começar?}

A Figura 1 destaca as principais etapas da pré-redação.

\subsubsection{Definição do tema e objetivos do trabalho}

No caso de relatórios de graduação, geralmente o tema e o delineamento geral dos objetivos são definidos no momento em que o professor requisita sua confecção. Por exemplo, em um relatório de uma disciplina de mapeamento, o objetivo principal será a obtenção do mapa da área delimitada. As instruções sobre o tema, objetivos e detalhes de como o relatório deve ser estruturado variam de acordo com cada disciplina. Em geral, o professor entrega as orientações impressas no início do curso. No entanto, muitas instruções são fornecidas oralmente, e o aluno deve estar atento a tais orientações.

\subsection{2 - Roteiro inicial/Estruturação}

Uma vez definidos o tema e os objetivos gerais, é possível estruturar o trabalho a partir do roteiro inicial e a busca bibliográfica. O roteiro inicial, ou estruturação básica do relatório, dependerá da definição dos capítulos nos quais o trabalho será dividido. Este primeiro roteiro servirá de guia para as fases de elaboração do trabalho e constituirá a base para o índice ou sumário final.

Segue abaixo modelo de estruturação básica de um relatório. Em algumas disciplinas o professor oferece o roteiro inicial do trabalho. Ele poderá ser modificado dependendo da natureza do trabalho, isto é, se revisão bibliográfica, trabalho de campo ou análise de dados, mapeamento, etc. Por exemplo, a geologia regional de determinada área pode ser o material de estudo em um relatório de revisão bibliográfica. Assim, o material (a geologia regional) e os métodos (se houver) seriam descritos em capítulos separados.

- Índice ou Sumário

- Lista de Figuras

- Lista de Tabelas

- 1. Resumo

- 2. Introdução

- 3. Material e Métodos

- 4. Resultados e Discussão

- 5. Conclusões

- 6. Referências

- Anexos

\subsection{3 - Busca e seleçã̃o de referências bibliográficas}

Como já observado por Oliveira e Sígolo (2005), este passo será a base de todo o trabalho, uma vez que a discussão sobre o tema tratado deve ser fundamentada em trabalhos anteriores, como artigos científicos e teses. Pode ser realizada com o auxílio de sítios de busca pela internet. O Google (http://www.google.com.br) é um sítio interessante para a busca inicial, mas devem ser utilizados sítios mais específicos para as Geociências, como o GeoRef (http://www.agiweb.org/georef/onlinedb/preview.html). Alguns portais, como o Portal da Pesquisa (http://portaldapesquisa.com.br), costumam hospedar as principais bases de dados bibliográficos da área.

Durante a busca, são selecionados os trabalhos adequados para a realização do relatório. Terminada esta tarefa, o aluno deverá obter os trabalhos selecionados, seja na forma impressa na biblioteca ou por via eletrônica. $\mathrm{O}$ acervo das bibliotecas das 
universidades públicas brasileiras inclui material impresso e assinaturas eletrônicas de grande número de periódicos científicos, que podem ser acessados pelas redes dessas instituições.

Os periódicos assinados pelas bibliotecas das universidades e institutos nacionais podem ser localizados na base de dados do IBICT (Instituto Brasileiro de Informação em Ciência e Tecnologia; http://ibict.br), por meio do acesso rápido ao CCN (Consulta ao Catálogo Coletivo Nacional; http:// ccn.ibict.br/busca.jsf). Da mesma forma, os portais das bibliotecas das universidades estaduais e federais do Brasil possuem acervos que reúnem obras impressas (como livros, periódicos, mapas, teses e dissertações). Muitas das obras possuem acesso eletrônico livre nos portais eletrônicos das bibliotecas de cada instituição.

Os trabalhos assim selecionados devem ser lidos e as informações e dados sintetizados. Buscas e seleções adicionais deverão ser altamente relevantes para o relatório e realizadas após cada uma das fases de execução, até que sejam reunidas as informações suficientes para atender os objetivos iniciais.

Muito embora não haja necessidade de citar todos os artigos já publicados sobre o assunto tratado, as referências selecionadas devem ser cronologicamente abrangentes. Sempre que possível, o relatório deverá contemplar os primeiros autores que definiram a unidade geológica ou conceitos utilizados, bem como os trabalhos mais importantes e recentes sobre o assunto. O número de referências utilizadas não precisa necessariamente ser alto, mas deve ser representativo e abrangente para assegurar a robustez do relatório.

A maior parte das referências é composta por trabalhos publicados em periódicos científicos arbitrados pelo sistema de revisão por pares (peer review). Os artigos são publicados somente após a avaliação do manuscrito por dois ou mais pesquisadores atuantes no tema geral do trabalho. $\mathrm{O}$ sistema de revisão busca assegurar a idoneidade do conteúdo do artigo e garantir que o conhecimento veiculado apresente qualidade e originalidade científicas. Alguns periódicos ainda aplicam a chamada revisão cega, na qual os avaliadores desconhecem a autoria do manuscrito em julgamento.

Secundariamente, também podem ser consultadas teses, dissertações, trabalhos de conclusão de curso e resumos em eventos científicos. Os resumos devem ser utilizados apenas quando trouxerem informações de extrema relevância para o relatório, ainda não disponíveis em periódicos arbitrados.
Livros e capítulos de livros também podem ser utilizados como fonte bibliográfica, mas aqueles considerados didáticos (que apresentam conceitos básicos sobre o tema) devem ser evitados, pois raramente representam fontes primárias de informações.

Jamais devem ser empregados textos de autoria desconhecida, como aqueles encontrados em sítios abertos de internet.

\section{2 - Confecção: da redação à finalização}

Após a fase de pré-redação, a confecção do trabalho se dará em duas fases principais: a redação do conteúdo e a finalização, isto é, a síntese e a verificação final do relatório como obra integrada e completa (Fig. 1).

\subsection{1 - Geologia Regional}

Esta fase será realizada com base nos artigos lidos na fase anterior, sempre tendo como foco os objetivos iniciais do relatório (Fig. 2). O capítulo sobre a geologia regional pode ser dividido em subitens, como "Conhecimento Prévio", ou "Síntese de Trabalhos Anteriores", e "Contexto Geológico Regional”, os quais tratam, respectivamente, do levantamento bibliográfico sobre a unidade geológica estudada do ponto de vista histórico, e a síntese consensual sobre a unidade em estudo.

Deste ponto em diante, recomenda-se que a lista de referências bibliográficas seja atualizada conforme as citações ao longo do texto em elaboração, de modo a evitar citações de referências faltantes ou referências listadas mas não citadas no texto. Também podem ser utilizados programas de gerenciamento e organização automática de referências, tais como Mendeley, EndNote, Papers, JabRef, BibTEX, entre outros.

Nesta fase também devem ser selecionadas e confeccionadas as figuras de localização, mapa geológico regional, coluna estratigráfica, e qualquer outro material visual de apoio pertinente à geologia regional.

\subsection{2 - Material e Métodos}

Por "material" entende-se o objeto de estudo. Em trabalhos como mapeamento, estratigrafia e petrografia, a própria geologia regional pode ser considerada o objeto de estudo do relatório. Por isso, é muito comum que após a seção de geologia regional sejam apresentados os métodos, sem que 
se coloque separadamente o item de materiais.

Os métodos são os procedimentos utilizados para o levantamento e análise dos dados. O termo "metodologia" deve ser empregado somente nos casos de estudo do método, ou mesmo quando da comparação de diferentes métodos (Jost e Brod 2005, Amaral, texto inédito, p. 41).

Os métodos devem ser redigidos de forma direta e clara, para que outros pesquisadores possam repetir os procedimentos. Métodos amplamente conhecidos não necessitam de detalhamento. Por outro lado, aqueles mais raramente empregados ou recentemente descritos na literatura devem ter os autores originais citados (Jost e Brod 2005, Oliveira e Sígolo 2005). Preferencialmente, os métodos devem ser escritos na ordem cronológica em que foram empregados ao longo do trabalho (Airola et al. 2000). Marcas, modelos de equipamentos, nomes e marcas registradas de programas devem ser especificados (Oliveira e Sígolo 2005).

Esta seção não deve incluir resultados ou interpretações.

\subsection{3 - Resultados e início da Discussão}

Os resultados devem ser apresentados de forma a levar o leitor a acompanhar a discussão posterior. Resultados numéricos podem ser resumidos em figuras, gráficos, ilustrações, diagramas, quadros e esquemas (G. Amaral, texto inédito). Diagramas e tabelas também são úteis para facilitar a compreensão dos dados, e também para a comparação dos resultados obtidos com os dados discutidos na literatura.

Os relatórios de revisão bibliográfica não incluem resultados analíticos. Por outro lado, os relatórios que envolvem coleta e análise de dados devem incluir a descrição dos resultados levantados em campo e eventualmente análise de amostras preparadas em laboratório. A caderneta de campo é importante nesta etapa como fonte de informações sobre as atividades de campo e materiais coletados.

Após a leitura crítica da bibliografia levantada, pode ser redigida a discussão inicial desses resultados comparando-os com outros estudos. Em alguns casos, os resultados e a discussão podem ser reunidos em uma mesma seção, mas eles devem ser organizados separadamente (como subitens, por exemplo).

A aplicação de novos métodos, bem como a descoberta de novos afloramentos, pode resultar em dados inéditos, os quais devem ser abordados na discussão. Dados inéditos, assim como resultados negativos, devem ser descritos nos resultados e suas implicações discutidas. A discussão deve abordar os argumentos levantados na introdução e a comparação dos resultados com outros trabalhos relevantes. No entanto, jamais deve conter a repetição dos resultados ou revisão bibliográfica mais extensa.

\subsection{4 - Introdução e finalização da Discussão}

Muitas vezes o aluno encontra dificuldade em iniciar o trabalho porque começa o relatório pela introdução. É mais fácil redigir a introdução após escrever sobre a geologia, métodos, resultados e início da discussão, ou seja, quando se domina o tema com mais propriedade.

A introdução não deve conter detalhes de geologia regional nem resultados ou conclusões. Ela deve apenas apresentar ao leitor o assunto geral, que será tratado de forma mais detalhada nas outras sessões do trabalho. É na introdução que o leitor se informa sobre a localização do material estudado, a problemática geral envolvida e a importância do estudo. Jost e Brod (2005) sugerem que na introdução devem constar a formulação geral do problema, o estado da arte sobre seu conhecimento, a localização da área, os objetivos e a abordagem utilizada.

Até este ponto, o aluno tem maior domínio sobre o assunto e é capaz de finalizar as discussões, de acordo com as informações fornecidas na introdução e os objetivos levantados.

É importante notar que todas as fases anteriores formam a base para o término da discussão. É na discussão em que se busca ligar as questões levantadas na introdução, incluindo as ideias da literatura mencionadas, com a interpretação dos resultados obtidos. Nesta fase é comum a necessidade de consultar referências bibliográficas adicionais para aprofundar a discussão dos resultados.

\subsection{5 - Conclusões}

As conclusões devem incluir apenas as deduções alcançadas a partir dos aspectos previamente discutidos. Não devem repetir resultados ou discussão. Devem ser elaboradas de modo simples e direto, e podem ser apresentadas sob a forma de itens. É importante conferir se os objetivos apresentados inicialmente foram contemplados nas conclusões. 


\subsection{6 - Resumo}

É a partir do resumo que o leitor decide se vai ler o restante do documento. Por isso, o resumo deve conter a síntese do trabalho realizado, e deve ser redigido somente após a confecção das outras seções do relatório. Esta síntese deve apresentar o contexto geral, bem como os principais resultados e conclusões, de forma concisa e informativa. $\mathrm{O}$ aluno deve ficar atento para não incluir no resumo a mera repetição do título (Jost e Brod 2005). O resumo também não deve incluir citações bibliográficas. No caso dos relatórios, o professor pode utilizar o resumo para avaliar se os alunos foram capazes de sintetizar os pontos principais do tema abordado.

\subsection{7 - Verificação}

Deve-se conferir o índice/sumário e verificar se cada seção do trabalho complementa a anterior. Deve-se também verificar se as citações ao longo do texto constam na lista de referências e vice-versa. Por fim, faz-se a verificação da organização dos anexos/apêndices e a confecção da capa.

Esta fase vai revelar a atenção e o cuidado com que o trabalho foi realizado. Muitas ocorrências de paginação errada, referências inexistentes ou não citadas, bem como a discrepância entre objetivos e conclusões podem sugerir que o trabalho foi finalizado às pressas.

\section{5 - Estilo do texto}

O estilo de redação é naturalmente pessoal, mas algumas diretrizes podem ser adotadas para delinear o formato geral e tornar o texto de fácil leitura. Textos científicos devem ser apresentados em linguagem simples, mas formal, cujo foco é a apresentação de dados e interpretações sobre determinado tema para a comunidade científica. Erros gramaticais, gírias, expressões coloquiais ou regionais - considerados como parte do estilo em alguns textos literários - são inaceitáveis em textos acadêmicos ou científicos. Também devem ser evitadas frases desnecessariamente longas, redundantes ou repetições de ideias.

Jost e Brod (2005, p. 7) resumem as principais características de estilo que os textos acadêmicos em Geociências devem conter: coerência e ênfase para alcançar a elegância, "clareza para não confundir os objetivos, simplicidade para compreensão fácil e concisão para leitura ágil”.

Muito raramente se obtém um texto adequado em sua primeira versão. Por este motivo, precisa-se de tempo e dedicação para se trabalhar o texto em suas diversas versões até sua forma final. Além disso, reler o texto após um intervalo de alguns dias ou mesmo semanas pode auxiliar no amadurecimento das ideias ali expressas e detectar erros gramaticais e de digitação. Relatórios redigidos às pressas jamais alcançam a qualidade desejada. Trabalhos em grupo podem resultar em relatórios mais ricos, já que cada integrante pode contribuir aos poucos para a qualidade do texto.

\section{6 - Plágio}

Os autores de conceitos, ideias e resultados extraídos de artigos, livros, monografias e outros trabalhos publicados apresentados no relatório devem ser citados ao longo do texto e a referência correspondente incluída na seção de referências. A citação da autoria é essencial para se evitar incorrer em plágio, considerado crime previsto no artigo 184 do Código Penal e cuja sanção é pena de três meses a um ano ou multa. O plágio não se traduz apenas em um conjunto de normas de forma e estilo de texto. É uma prática que alcança os limites da ética ao configurar "imitação fraudulenta de uma obra" (Moraes 2007, p. 95). Daí ser considerado crime. Deve-se atentar para o fato de que o plágio ocorre não somente quando trechos de obras publicadas são copiados literalmente sem a citação do autor. A paráfrase, que constitui a reprodução de ideias, modelos, concepções ou conceitos sem o uso literal do texto original, também pode representar plágio se estiver desacompanhada da citação do autor.

O plágio em ambiente acadêmico tem sido amplamente debatido em países estrangeiros e a tolerância a essa prática por parte das agências de fomento e revistas científicas internacionais tem sido cada vez menor (Vasconcelos 2007). Mais recentemente este assunto tem se acalorado também no Brasil, sobretudo após casos confirmados de plágio em universidades brasileiras, que envolveram processos judiciais resultando em demissões de docentes e perda de títulos por parte de alunos. Foi proposta ao Conselho Federal da Ordem dos Advogados do Brasil (Proposição número 2010.19.07379-01) a ementa (número 34/2010/ $\mathrm{COP}$ ) que aborda a prática de plágio nas instituições de ensino e o comércio ilegal de monografias (Paiva 2010).

Embora comum em trabalhos escolares brasileiros de Ensino Fundamental e Médio (Silva 
2008), o plágio jamais deve ocorrer em ambiente acadêmico, seja em relatórios de graduação, seja em artigos científicos ou textos de outra natureza. É imprescindível que o aluno compreenda a gravidade existente na prática de plágio e estar sempre atento: a transcrição de trechos ou utilização de ideias de obras publicadas deve ser acompanhada da citação do autor que as criou. A forma de citar dependerá das normas adotadas (veja exemplos na próxima seção).

\section{7 - Formalidades}

As formalidades correspondem a um conjunto de regras de estilo de formatação adotadas ao longo de todo o documento. Existem diversas normas de formatação que podem ser adotadas. Em textos nacionais, é comum a adoção das normas estabelecidas pela Associação Brasileira de Normas Técnicas (ABNT 2002/ NBR6023). Para textos internacionais e alguns nacionais redigidos em língua inglesa existem diversos conjuntos de normas, sendo mais comumente adotado o Manual de Publicações da Associação Americana de Psicologia (APA 2009).

\section{1 - Capa}

$\mathrm{Na}$ capa devem constar as informações básicas sobre o relatório, nesta sequência: instituição (Universidade e Instituto), código e nome da disciplina, título do relatório, nome completo do aluno ou de cada integrante do grupo e data. No caso de relatórios individuais e curtos (menos de 10 páginas), recomenda-se colocar as informações da capa na porção superior da página e no restante da página o índice/sumário. Para relatórios longos ou que sejam desenvolvidos em grupo, sugere-se utilizar toda a página para as informações da capa.

\section{2 - Apresentação e formatação do texto}

Os relatórios devem ser impressos em papel sulfite A4. Se o papel tiver gramatura baixa $(75 \mathrm{~g}$ / $\mathrm{m}^{2}$ ), recomenda-se imprimir uma página por folha, pois partes do texto e figuras podem transparecer parcialmente no verso. Se for utilizado papel com gramatura maior (acima de $90 \mathrm{~g} / \mathrm{m}^{2}$ ), sugere-se imprimir nos dois versos da folha. No caso de se utilizar papel sulfite reciclado, é recomendável a confecção de figuras apenas em escala de cinza, para evitar que a coloração do papel interfira no padrão de coloração das figuras.
Tanto trabalhos monográficos (relatórios, trabalhos de formatura, dissertações e teses), como manuscritos para serem submetidos à publicação em periódicos científicos, devem ser editados em uma coluna. No caso de monografias e relatórios, as margens comumente são apresentadas $\operatorname{com} 2 \mathrm{~cm}$.

Recomenda-se adicionar um espaço de parágrafo antes dos títulos e subtítulos. Os resumos devem ser formatados ligeiramente diferentes em relação ao restante do texto (veja abaixo).

Trabalhos com poucas páginas (até 30) podem ser apenas grampeados no canto superior esquerdo. Já trabalhos mais extensos devem ser encadernados. A encadernação pode ser feita grampeando-se toda a margem esquerda do trabalho, em pasta com presilha, ou com espiral e capa e contracapa plásticas. Outra forma é apresentar o texto em pastas do tipo documento (com lombada solta para prender as folhas). A encadernação requer uma margem maior, de $3 \mathrm{~cm}$. Se a impressão for feita em frente e verso, as páginas ímpares devem ter a margem esquerda maior, enquanto as páginas pares devem ter a margem direita maior. Sugere-se consultar o professor a respeito do tipo mais adequado de encadernação para facilitar a manipulação do trabalho durante a correção e avaliação.

A numeração das páginas pode seguir dois modelos. No primeiro, todas as páginas são numeradas (em algarismos arábicos), com exceção da capa e índice. A contagem das páginas deve se iniciar após a capa, mas ser impressa somente a partir da primeira página da introdução. Por exemplo: o relatório tem a primeira página com a capa, a segunda com o índice, a terceira com o resumo e palavras-chave, e a introdução se inicia na quarta página. Como a capa não é contada e a numeração deve ser impressa somente a partir da introdução, a paginação começará a partir da página 3 , no capítulo introdução.

No segundo modelo, as páginas iniciais após a capa (índice, resumo etc.) são numeradas com algarismos romanos minúsculos (i, ii, iii, iv etc.) e as páginas restantes com algarismos arábicos, a partir de 1. Em ambos os casos os números devem ter a mesma localização na página (direita, centralizada ou esquerda e inferior ou superior, mas sem variar).

Cada anexo/apêndice deve ter paginação independente do corpo do texto, seja ela em algarismos romanos ou arábicos (por exemplo, cada anexo começa da página 1, i ou I).

Os títulos de primeiro nível de hierarquia (isto é, cada capítulo) podem ser iniciados em nova 
página.

Para facilitar a leitura, recomenda-se o uso de fontes serifadas no corpo do texto e fontes sem serifas nos títulos e subtítulos. As serifas são os traços sutis existentes na base de alguns conjuntos de letras que acabam formando uma baliza quase contínua na porção inferior da linha do texto. Com isso, auxiliam na leitura de grandes blocos de texto, como aqueles em página de tamanho A4 e coluna única. Alguns exemplos de fontes serifadas são: Times New Roman, Garamonde Bookman. Já as letras sem serifas são mais utilizadas em títulos, porque tendem a valorizar cada uma das poucas palavras existentes, e dão a eles um aspecto mais limpo. Alguns exemplos de fontes sem serifas: Arial, Calibri e Tahoma. O tamanho padrão para textos de relatórios é 12, com espaço entre linhas de 1,5 pontos.

\section{3 - Índice/Sumário}

O índice ou sumário apresenta a estrutura do trabalho (Resumo, Introdução, Material e Métodos, Resultados, Discussão, Conclusões etc.) hierarquizada e com indicação das páginas.

O emprego desses termos na divisão em itens da estrutura do trabalho é tema controverso. O termo em latim, index, significa acusador, denunciador, inscrição, título, sinal, indício (Cintra e Cretela 1944). O termo em inglês (index) é utilizado como índice remissivo e, assim como em português, é originado do latim. Os termos table of contents ou simplesmente contents costumam ser utilizados em livros de língua inglesa para indicar a lista inicial de capítulos com a respectiva indicação das páginas. Na prática, é uma convenção adotada por editores estrangeiros para indicar o índice remissivo que passou a ser utilizada também no Brasil (N. Tudrey 2013, comunicação verbal). Entretanto, a palavra "índice" já existia na língua portuguesa com significado próprio previamente à criação da convenção do termo em inglês. O termo em inglês table of contents não foi traduzido, e usa-se a palavra "sumário" na divisão do trabalho apresentada antes da introdução. A norma NBR 10719 (ABNT 1989) não é muito clara a esse respeito, pois ora não distingue claramente os termos, ora considera "índice" como sinônimo de índice remissivo e "sumário" como a lista inicial dos capítulos de um relatório, trabalho acadêmico ou livro. Monteiro (1998) fez uma breve discussão sobre o assunto e detalha os pontos nos quais a norma NBR 10719 (ABNT 1989) parece duvidosa quanto à definição e conceituação da terminologia. Este guia não pretende investigar profundamente qual termo deve ser usado, mas levanta um questionamento que está longe de ser respondido. Por esse motivo, a melhor forma de se decidir sobre o emprego de "índice" ou "sumário" é perguntar ao professor responsável pela disciplina sua preferência sobre cada um dos termos.

A hierarquia dos títulos e subtítulos deve ser uniformizada para que o leitor acompanhe os níveis organizados pelos autores. Deve conter os três primeiros níveis hierárquicos numerados e as páginas correspondentes. Subtítulos de quarto nível de hierarquia (por exemplo, 1.1.1.1) não devem constar do índice/sumário. Se necessários, devem ser apresentados somente ao longo do texto, sem numeração, e formatados de modo a se destacarem do texto pelo recurso itálico ou negrito. Também não se deve subdividir um título (capítulo) em apenas um subtítulo. Os anexos, assim como as listas de figuras e tabelas, podem ou não ser incluídos na numeração hierárquica do índice/sumário.

\section{4 - Resumo e palavras-chave}

A extensão do resumo no caso de relatórios varia de acordo com o tema abordado, mas se recomenda não ultrapassar uma página. Embora não seja regra, os resumos são geralmente apresentados em parágrafo único, tamanho de fonte um ponto a menos do que o corpo do texto (em geral 11) e espaço simples entre linhas. Jamais devem conter citações de referências.

Após o parágrafo do resumo, devem ser apresentadas as palavras-chave (de três a sete), que são palavras ou expressões relacionadas ao tema do trabalho. As palavras-chave são importantes por serem utilizadas em sistemas de busca para localização de trabalhos com temas específicos. Deve-se evitar citar palavras que já façam parte do título do trabalho.

\section{5 - Nomes de unidades geológicas e taxonômicos}

Os nomes das unidades geológicas devem estar acompanhados pela categoria correspondente e serem iniciados com letras maiúsculas. Por exemplo: Bacia do Paraná, Grupo Tubarão, Subgrupo Guatá, Formação Rio Bonito. Quando utilizadas unidades geológicas cuja categoria varia de acordo com o autor, a adoção de determinada categoria deve ser especificada e citado o autor que a propôs. Se apenas uma mesma categoria for utilizada, 
esta deve ser empregada de maneira uniforme ao longo do texto. Neste caso, pode-se mencionar o autor apenas na primeira vez em que for citada. Do contrário, cada categoria deve vir acompanhada do autor correspondente. Por exemplo: "Subgrupo Irati (de acordo com Hachiro et al. 1993)"; "Formação Irati (de acordo com White 1908)".

Já os nomes científicos de organismos devem ser destacados com o recurso itálico. Após a primeira apresentação no texto, o nome genérico pode ser abreviado. Por exemplo: Baurusuchus salgadoensis deve ser grafado por extenso na primeira vez em que for citado; nas vezes seguintes, o nome do gênero pode ser abreviado, mantendo-se o nome por extenso da espécie: B. salgadoensis. No caso de exemplares identificados até o nível de gênero apenas, esta categoria deve ser informada por extenso em todos os pontos do texto onde for citada, estando a indicação de espécie abreviada sem o destaque itálico. Por exemplo: Baurusuchus sp. Tanto nas tabelas e como nas figuras, o nome deve ser escrito por extenso, inclusive nas legendas, para que o leitor não precise recorrer ao texto para se informar do nome completo da espécie.

Nomes de minerais podem ser abreviados utilizando-se a notação de Kretz (1983) ao se tratar da descrição de litotipos. Dessa forma, um cianita-granada-muscovita quartzito pode ser abreviado para Ky-Grt-Ms quartzito, e um muscovita-biotita-quartzo xisto pode ser escrito Ms-Bt-Qtz xisto (mas não "ms-bt-qzo xisto"). O mesmo vale para paragêneses minerais. Por exemplo: "as rochas metapelíticas preservam paragêneses de alta pressão (Rt-Ky-Grt-Ms-Bt-Pl-Qtz)”.

\section{6 - Palavras estrangeiras}

As palavras estrangeiras devem ser utilizadas com cautela, já que o excesso de termos em outra língua atrapalha a fluidez do texto. Quando imprescindíveis, devem estar em itálico, como nappe (do francês) ou klippe (cujo plural é klippen, do alemão). Em vários casos, termos estrangeiros podem ser substituídos por palavras em português, como "sítio" em vez de site para se referir a um endereço da internet. O termo "software", por exemplo, não tem plural em sua forma original em inglês, o que pode causar estranheza à primeira vista, como na frase "foram utilizados três software diferentes para a análise estatística dos dados". Este problema pode ser contornado ao se substituir o termo original pelo equivalente em português; no caso do exemplo: "programa de computador" ou "aplicativo".

\section{7 - Citações no texto}

As citações ocorrem sempre que se utilizam trechos, conceitos ou ideias de obras já publicadas. Devem ser utilizadas para evitar a prática de plágio (veja seção anterior). As citações podem ser diretas ou indiretas, dependendo se ocorre a transcrição literal de trechos ou nova redação. Existe também a chamada "citação de citação", ou transcrição indireta.

\section{8 - Citações diretas}

Também chamadas de transcrições diretas ou literais, correspondem a trechos extraídos integralmente de outros trabalhos e apresentados em sua forma original. Os trechos devem estar delimitados por aspas e acompanhados pelos dados da publicação, incluindo o número da página do excerto. Transcrições de textos mais longos que três linhas inteiras devem ser separadas do corpo do texto. Exemplo:

Tanto a litologia observada nos afloramentos como a do meio da bacia, conhecida graças à sondagem da Petrobrás, mostram-se de uma uniformidade impressionante. (Amaral 1967, p. 8).

\section{9 - Transcrições indiretas}

Chamadas comumente de "citação de citação", ocorrem quando uma citação é realizada a partir de uma já feita por outro autor. Esse tipo de citação deve ser evitado, e empregado somente quando o trabalho original for inacessível, o que geralmente ocorre nos casos de obras raras e antigas. É importante acessar a publicação original para se certificar de que as informações citadas por determinado trabalho constam, de fato, no original. Desta forma, evita-se a chamada "propagação do erro bibliográfico" (G. Amaral, texto inédito, p.27).

Quando esse tipo de citação for imprescindível, pode-se empregar a expressão 'citado em' ou apud (do latim "em" ou "junto de"), e pode-se incluir na lista de referência apenas a publicação utilizada. Exemplo:

Um método comum empregado na Paleontologia para definição de espécie é o tipológico, o qual, segundo Bernard (1896, citado em Mayr 1964), reflete o conhecimento do especialista, e não necessariamente a história natural do grupo. 
No exemplo, pode-se incluir na lista de referências apenas Mayr (1964) ou Mayr (1964) e Bernard (1986).

\subsection{0 - Citações indiretas}

São usadas quando apenas a ideia ou conceito são mantidos da obra original. É o tipo mais recomendado de citação, pois denota mais maturidade do texto, além de resultar em leitura mais fluida. Há duas formas de citações indiretas: por número e autor-data.

O sistema por número é mais adotado em obras literárias e, no caso de textos acadêmicos, em algumas revistas científicas. Por exemplo: "Segundo a classificação adotada". Os dados bibliográficos referentes a cada número sobrescrito são detalhados em notas de rodapé ou ao final do texto, em uma lista de referências organizada por ordem de citação.

O sistema autor-data é aquele em que o sobrenome do autor e o ano da publicação são citados junto ao texto. Para relatórios de disciplina, a forma mais adequada é a citação por autor-data.

Além disso, o nome do autor pode fazer parte da sentença, ou ser mencionado entre parênteses. Por exemplo: "Segundo a classificação de Miall (1996)", ou "Segundo a classificação adotada (Miall, 1996)". Embora o emprego de uma ou outra forma de citação indireta dependa do estilo pessoal do redator do texto, a menção do autor entre parênteses costuma resultar em textos de leitura mais fluida e agradável.

Dependendo do conjunto de normas adotado, alguns detalhes empregados nas citações ao longo do texto podem variar. Assim, os nomes dos autores citados podem ser grafados com a primeira letra em maiúscula e as demais minúsculas, ou totalmente em maiúsculas. Uma vez adotado um estilo, o mesmo deve ser utilizado ao longo de todo o documento. Por exemplo: Petri (1958) ou PETRI (1958). O ano pode ou não ser separado do autor por vírgula. Exemplos: Miall 1996 ou Miall, 1996. Pode-se usar vírgula ou ponto-e-vírgula para separar citações de diferentes trabalhos de um mesmo autor. Exemplos: (Almeida 1949, 1984) ou (Almeida, 1949; 1984). Pode-se ainda adotar o uso do "e" tironiano, cujo símbolo é " $\&$ ", para citações com dois autores. Este é um sinal que representa a conjunção latina $e t$, e pode ser empregado para simbolizar que a autoria da publicação é formada apenas por dois autores, evitando-se confundir essa condição com a de uma publicação de apenas um autor cujo nome é composto. Exemplos: Riccomini e Coimbra (1992) ou Riccomini \& Coimbra (1992).

Outros elementos, entretanto, devem ser obedecidos para facilitar a leitura e recuperação das informações de publicação na lista de referências. Dessa forma, usam-se letras minúsculas para separar trabalhos de um mesmo autor publicados num mesmo ano. Exemplo: (Hasui 1975a, b). Os trabalhos devem ser citados em ordem cronológica. Exemplo: Almeida 1949, Ab’Sáber 1972, Hasui 1975. No caso de trabalhos com três autores ou mais, utiliza-se a notação "et al." (que pode ou não estarem itálico e seguida de ponto) que é a abreviação em latim para "e outros". Exemplo: Giannini et al. 2004.

\subsection{1 - Referências bibliográficas}

As citações ao longo do texto devem ter suas informações de publicação organizadas após o texto em ordem alfabética na lista de referências bibliográficas, em seção distinta e denominada "Referências". Podem ser organizadas pela ordem de citação no caso do uso do sistema de citação numérico. No entanto, como se recomenda que os relatórios de disciplina adotem o sistema autor-data, abordaremos aqui somente esses exemplos.

A organização por ordem alfabética de autor facilita a recuperação dos dados bibliográficos de referências de interesse ao leitor. Nos casos de publicações de um mesmo autor em anos diferentes, as referências devem ser apresentadas em ordem cronológica. E, nos casos de diversas publicações de um mesmo autor em colaboração com outros dois ou mais, deve-se respeitar a ordem cronológica das publicações, e não alfabética do segundo autor.

A forma como os dados de cada referência devem ser apresentados varia de acordo com a norma adotada. A Tabela 1 lista exemplos para organização das referências bibliográficas segundo o estilo de regras da ABNT e segundo as diretrizes para publicação no periódico nacional Brazilian Journal of Geology (BJG 2013), as quais se baseiam nas normas da APA (2009). De forma geral, o estilo APA ocupa menos espaço do que o estilo ABNT, além de ter as informações básicas de citação (autores e ano) sequenciais, o que facilita a localização de determinada referência na lista.

Já que não há regras rígidas para o emprego de um conjunto de regras específico em relatórios de graduação, fica a critério do professor da disciplina 
Tabela 1. Exemplos de organização de referências bibliográficas de acordo com as normas estabelecidas pela Associação Brasileira de Normas Técnicas (ABNT 2002) e baseados nas diretrizes da Brazilian Journal of Geology (BJG 2013).

\begin{tabular}{|c|c|}
\hline & EEFERÊNCIA \\
\hline \multirow{4}{*}{ 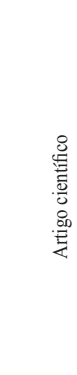 } & Um autor \\
\hline & Dois autores \\
\hline & Vários autores \\
\hline & Aceito, mas ainda não publicado \\
\hline \multirow{2}{*}{ 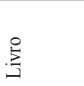 } & Edição única \\
\hline & Mais de uma edição \\
\hline
\end{tabular}

ABN

RICCOMINI, C. Arcabouço estrutural e aspectos do tectonismo gerador e deformador da Bacia Bauru no Estado de São Paulo. Revista Brasileira de Geociências, v. 27, p. 153-162, 1997. ALVARENGA, C.J.S.; TROMPETTE, R. Evolução tectônica Brasiliana da Faixa Paraguai: a estruturação da região de Cuiabà. Revista Brasileira de Geociências, vol. 23, n.1, p. 18-30, 1993. ATENCIO, D.; COUTINHO, J.M.V.; DORIGUETTO, A.C.; MASCARENHAS, Y.P.; ELLENA, J.; FERRARI, V.C. Menezesite, the first natural heteropolyniobate, from Cajati, São Paulo, Brazil: description and crystal structure. American Mineralogist, vol. 93, p. 81-87, 2008.

RUBERTI, E.; COMIN-CHIARAMONTI, P.; AZZONE, R.G.; ENRICH, G.E.R.; DE MIN, A.; GOMES, C.B. Petrogenesi of Early Cretaceous potassic alkaline rocks from the Banhadão Complex, Southeastern Brazil. Mineralogy and Petrology, No prelo.

ANELLI, L.E. O Guia Completo dos Dinossauros do Brasil. São Paulo: Editora Peirópolis, 2010.222 p.

ZAR, J.H. Biostatistical Analysis. Second Edition, Englewood Cliffs: Prentice Hall, 1984. $1120 \mathrm{p}$

GIANNINI, P.C.F.; ASSINE, M.L.; SAWAKUCHI, A.O. Ambientes eólicos. In: PEDREIRA, A.J.; ARAGÃO, M.A.N.F.; MAGALHÃES, A.J. Ambientes de Sedimentação Siliciclástica do Brasil. São Paulo: Beca, 2006. p. 72-101.

Capítulo de livro

KARMANN, I. Ciclo da água, água subterrânea e sua ação geológica. In: TEIXEIRA, W.; TOLEDO, M.C.M.; FAIRCHILD, T.R.; TAIOLI, F. Decifrando a Terra. $1^{\text {a }}$ edição, São Paulo: Oficin de Textos, 2000. p. 114-136.

TICKELL, C. Foreword. In: LOVELOCK, J.E. The Revenge of Gaia: Earth's Climate Crisis and the Fate of Humanity. New York: Perseus Books, 2006. p. xv-xvii.

CRUZ JÚNIOR, F.W. Sistemas deposicionais, geomorfologia e geologia estrutural de uma área na Região de Felipe Guerra, Sudoeste da Bacia Potiguar. 1996. Monografia de Conclusão de

Monografia Curso - Centro de Ciências Exatas e da Terra, Universidade Federa do Rio Grande do Norte, Natal, RN.

MORAES, R. Metamorfismo e deformação da seqüência vulcanosedimentar Juscelândia, GO, e geoquímica dos seus Anfibolitos.

Dissertação 1992. Dissertação de Mestrado - Instituto de Geociências, Universidade de Brasília, Brasília, DF,

ALMEIDA, R.P. Tectônica e sedimentação do Ediacarano ao

Ordoviciano: exemplos do Supergrupo Camaquã (RS) e do Grupo Caacupé (Paraguai Oriental). 2005. Tese de Doutorado - Instituto

Tese de Geociências, Universidade de São Paulo, São Paulo, SP. PRECIOZZI, F.; BASEI, M.A.S.; PEEL E.; BETTUCCI, L.S.; CORDANI, U.G.; OYHANTCABAL, P. Punta del Este Terrane: Mesoproterozoic basement and Neoproterozoic cover. In: IV

Impresso

SOUTH AMERICAN SYMPOSIUM ON ISOTOPE GEOLOGY AND IV SSAGI, 2003. Short Papers... Salvador, BA, 2003. p. 660-661.

Riccomini C. 1997. Arcabouço estrutural e aspectos do tectonismo
gerador e deformador da Bacia Bauru no Estado de São Paulo. Revista Brasileira de Geociências, 27: 153-162.

Alvarenga C.J.S., Trompette R. 1993. Evolução tectônica Brasiliana da Faixa Paraguai: a estruturação da região de Cuiabá. Revista Brasileira de Geociências, 23(1): 18-30.

Atencio D., Coutinho J.M.V., Doriguetto A.C., Mascarenhas Y.P., Ellena J., Ferrari V.C. 2008. Menezesite, the first natural heteropolyniobate, from Cajati, São Paulo, Brazil: description and crystal structure. American Mineralogist, 93: 81-87.

Ruberti E., Comin-Chiaramonti P., Azzone R.G., Enrich G.E.R., De Min A., Gomes C.B. (no prelo). Petrogenesis of Early Cretaceous potassic alkaline rocks from the Banhadão Complex, Southeastern Brazil. Mineralogy and Petrology.

Anelli L.E. 2010. O Guia Completo dos Dinossauros do Brasil. São Paulo, Editora Peirópolis, 222p.

Zar J.H. 1984. Biostatistical Analysis. Second Edition, Englewood Cliffs, Prentice Hall, 1120p.

Giannini P.C.F., Assine M.L., Sawakuchi A.O. 2006. Ambientes eólicos. In: Pedreira A.J., Aragão M.A.N.F., Magalhães A.J. (orgs.) Ambientes de Sedimentação Siliciclástica do Brasil. São Paulo, Beca, p. 72-101.

Karmann I. 2000. Ciclo da água, água subterrânea e sua ação geológica. In: Teixeira W., Toledo M.C.M., Fairchild T.R., Taioli F. (orgs.) Decifrando a Terra. $1^{a}$ edição, São Paulo, Oficina de Textos, p. 114-136.

Tickell C. 2006. Foreword. In: Lovelock J.E. (ed.) The Revenge of Gaia: Earth's Climate Crisis and the Fate of Humanity. New York, Perseus Books, p. xv-xvii.

Cruz Júnior F.W. 1996. Sistemas deposicionais, geomorfologia e geologia estrutural de uma área na Região de Felipe Guerra, Sudoeste da Bacia Potiguar. Monografia de Conclusão de Curso, Centro de Ciências Exatas e da Terra, Universidade Federal do Rio Grande do Norte, Natal, 120p.

Moraes R. 1992. Metamorfismo e deformação da seqüência vulcanosedimentar Juscelândia, GO, e geoquímica dos seus Anfibolitos. Dissertação de Mestrado, Instituto de Geociências, Universidade de Brasília. Brasília, 171p.

Almeida R.P. 2005. Tectônica e sedimentação do Ediacarano ao Ordoviciano: exemplos do Supergrupo Camaquã (RS) e do Grupo Caacupé (Paraguai Oriental). Tese de Doutorado. Instituto de Geociências, Universidade de São Paulo, São Paulo, 203p.

Preciozzi F., Basei M.A.S., Peel E., Bettucci L.S., Cordani U.G., Oyhantcabal P. 2003. Punta del Este Terrane: Mesoproterozoic basement and Neoproterozoic cover. In: IV South American Symposium on Isotope Geology and IV SSAGI. Salvador, Short Papers, p. 660-661.

Carraro C.C., Gamermann N., Eick N.C., Bortoluzzi C.A., Jost H., Pinto J.F. 1974. Mapa Geológico do Estado do Rio Grande do Sul, escala 1:1.000.000. Porto Alegre, Instituto de Geociências da UFRGS.

World Meteorological Organization - WMO. 2009. Winners of the Norbert Gerbier-Mumm International Award. <http://www.wmo.ch pages/about/awards/winners mumm. html $>$. Acesso em 08/dez/2009.

INGÁ (Instituto de Gestão das Águas e Clima). 2008. RPGA dos rios Pardo e Jequitinhonha. Relatório Técnico, 44p. 
ou mesmo do aluno a adoção da norma. Uma vez selecionado o conjunto de regras, que pode ainda ser diferente dos exemplos da tabela 1, o estilo adotado deve ser mantido ao longo de toda a lista de referências, para que o produto final seja uniforme.

É importante salientar ainda que, no caso de dados inéditos obtidos verbalmente, indica-se somente a fonte da comunicação no corpo do texto. A fonte não é incluída nas referências, já que não há dados de publicação para serem informados. Exemplo: "B.B. Brito-Neves (comunicação pessoal)" ou "B.B.Brito-Neves (resultados não publicados)".

\section{8 - Elementos de apoio ao texto}

Figuras e tabelas podem ser utilizadas como material de apoio para ilustrar algum aspecto levantado no texto em diversas seções, como introdução, material e métodos, resultados e discussão. Assim, são recursos utilizados para mostrar ao leitor a localização de área, padrões obtidos com base em algum método específico ou mesmo organizar dados. As figuras incluem mapas, esquemas, diagramas, croquis, fotografias e gráficos. Tais recursos somente devem ser utilizados se informativos e necessários, ou seja, quando auxiliarem na abordagem do assunto tratado no texto. Além disso, são autoexplicativos, ou seja, capazes de levar o leitor à compreensão da ideia apresentada com dependência mínima do texto.

Jost e Brod (2005) destacaram que o planejamento de cada figura, gráfico ou tabela em textos acadêmicos deve ser avaliado quanto à sua finalidade, grau de relação com o texto, opções alternativas e dimensões. Assim, cada elemento deve contribuir efetivamente para a compreensão de uma ideia e formar um conjunto lógico e equilibrado com o texto. Gráficos são figuras específicas empregadas para demonstrar variações ou padrões de distribuição de dados. As tabelas são elaboradas somente quando se necessita resumir resultados, agrupar conjuntos de dados que serão comparados, reunir procedimentos e resultados experimentais, ou fornecer dados de forma que o procedimento possa ser reproduzido.

\section{1 - Figuras}

Como em Geociências os relatórios abordam estudos relacionados a unidades geológicas, eles sempre deverão apresentar uma ou mais figuras de localização e, dependendo do assunto, mapa geológico e coluna estratigráfica. Se o relatório incluiu trabalho de campo com coleta de amostras, os pontos e os níveis estratigráficos de coleta deverão ser indicados, respectivamente, no mapa geológico e na seção estratigráfica. Mapas de ponto, afloramentos, caminhamento, assim como croquis e perfis geológicos também são importantes para informar o leitor sobre a proveniência dos objetos de estudo ou mostrar como ocorreu o desenvolvimento do relatório.

\section{2 - Apresentação e formatação das figuras}

No caso de relatórios de mapeamento, geralmente os mapas e perfis confeccionados devem vir anexos, e não ao longo do texto. Nesses casos, o objetivo principal do relatório é a produção do mapa, o qual, geralmente é confeccionado em tamanho maior que A4.

Já figuras ilustrativas de aspectos mencionados ao longo do texto, como localização, mapas (geológicos ou geográficos) extraídos da literatura, gráficos, esquemas, fotos de campo, e quaisquer figuras que acompanhem os capítulos de Introdução, Material e Métodos ou Resultados devem estar inseridas ao longo do texto. É comum a composição múltipla de mapas ou imagens em diferentes escalas (A. Bartorelli 2014, comunicação verbal). Isto é importante para que o leitor localize mais facilmente a área de estudo em escala regional.

As figuras devem estar posicionadas após a primeira citação, e legendadas com algarismo arábico seguido de texto explicativo (veja exemplos nas figuras 2 e tabela 2). As legendas sempre devem vir abaixo das figuras e ser redigidas em espaçamento simples, justificadas ou centralizadas.

As figuras, incluindo os gráficos, devem apresentar tamanho harmonioso em relação à página e estar em resolução suficiente para se evitar o aspecto "pixelado" de figuras com resolução muito baixa. A resolução é definida pela densidade de elementos em uma imagem, ou seja, o número de pontos em uma determinada área. As medidas para impressão em papel são definidas por "dpi" (do inglês dots per inch, ou pontos por polegada). Para medidas de monitores, a unidade usada é "ppi" (do inglês pixels per inch, união da abreviatura em inglês de picture pix element, ou seja, elementos de imagem). Em geral, a resolução de tela é melhor do que em papel, devido à diferença entre os sistemas de formação de tonalidades e intensidades de cores utilizados em telas e impressoras. No entanto, é 


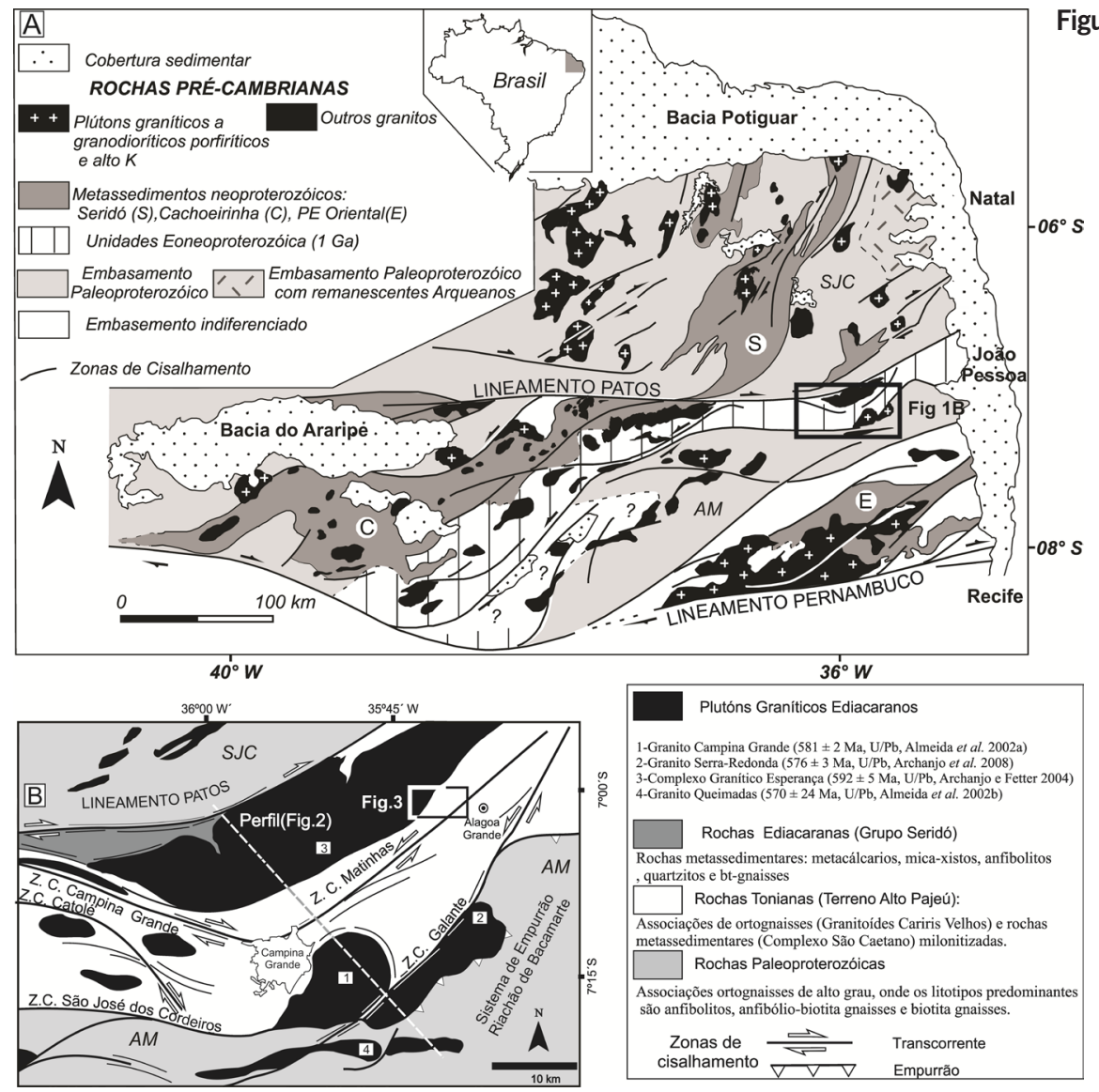

Figura 2. (extraída de Rodrigues et al. 2010). A. Contexto geológico e geotectônico regional da Província Borborema (modificado de Archanjo e Fetter 2004). B. Principais zonas de cisalhamento regionais e contexto geológico e localização da secção geológica regional (Figura 2) e do mapa geológico da área estudada (Figura 3). AM $=$ Alto Moxotó e SJC = São José do Campestre.

comum o uso de "dpi" tanto em tela como em impressoras. Pelo menos 300 dpi para fotos e 400 dpi para desenhos são níveis adequados de resolução para impressão.

Fotos também devem estar com resolução e enquadramento suficientes para que a estrutura seja facilmente observada na imagem. Se a imagem utilizada de um trabalho estiver em resolução baixa, a mesma deve ser redesenhada em programa adequado (por exemplo, Corel Draw).

Os símbolos e as palavras em figuras devem estar legíveis e devidamente explicados em suas respectivas legendas. Mapas, seções estratigráficas, perfis e fotos de afloramentos devem sempre vir acompanhados da legenda de cores ou texturas de preenchimento e simbologia padronizada das feições geológicas.

A escala deve ser adequada à área abrangida e deve ser indicada, assim como o norte, no caso de mapas e perfis. No caso de fotografias, deve-se atentar para o tamanho e posição da escala, bem como o tamanho do objeto fotografado em relação à área da imagem. Assim, a escala deve ser visível e posicionada na borda da imagem e o objeto ou feição deve ocupar a maior parte da área da imagem.

No caso de imagem extraída, modificada ou traduzida de trabalhos publicados, ou mesmo sintetizada a partir de várias, todas as referências originais devem ser informadas e incluídas na seção "Referências".

A figura 2 é um exemplo de mapa de localização e geológico (extraído de Rodrigues et al. 2010, p. 3) com todos os elementos essenciais para sua compreensão: indicação de norte, escala, legenda das unidades litoestratigráficas, convenções cartográficas e abreviações utilizadas. Note que a figura usa o recurso de composição múltipla de mapas, destacando a posição da área de estudo em contexto geológico regional e no Brasil. Além disso, como a figura foi confeccionada a partir de figuras de outros trabalhos, estes estão indicados no texto explicativo da legenda.

Se a figura utilizada for extraída de um trabalho originalmente escrito em inglês, todos os dizeres devem ser vertidos para o português, o texto da legenda reescrito e a fonte da figura indicada. 


\section{3 - Figuras impressas}

Como os relatórios geralmente devem ser entregues impressos, a configuração dos padrões gráficos utilizados no programa de desenho é importante. Os programas mais comumente empregados para confecção de desenhos são o Corel Draw, Adobe Illustrator, Canvas, Inskscape, entre outros. Se as figuras forem desenhadas com preenchimento em escalas de cinza, recomenda-se usar a paleta com intervalos de pelo menos $20 \%$ de escala, para que a diferença entre os padrões seja perceptível na figura impressa. Assim, podem ser utilizadas até seis variações de cinza da paleta, incluindo o branco e o preto $(0 \%, 20 \%$, $40 \%, 60 \%, 80 \%$ ou $100 \%$ de preto).

Muitas vezes, apenas as opções de tons de cinza não são suficientes para o preenchimento de todos os padrões necessários. Assim, podem-se utilizar cores ou mesmo símbolos. Porém, os símbolos que acompanham os programas de desenho não são adequados para a representação geológica. Em geral, é necessária a criação de símbolos e sua adição às opções de preenchimento do programa (Jost e Brod 2005). Se a qualidade da impressora for baixa, deve-se evitar usar linhas com espessura mínima, que provavelmente não serão nítidas na versão impressa. A figura 2 é um exemplo que mescla padrões de preenchimento e tons de cinza, e apresenta boa diferenciação dos tipos de rocha no mapa geológico.

Os sistemas de cores utilizados no programa de desenho e na impressora devem ser compatíveis, para que o tom de cor impresso não seja diferente daquele visualizado no monitor do computador. O sistema de reprodução de cor utilizado em monitores é o RGB (do inglês Red vermelho, Green - verde e Blue - azul), enquanto o sistema padrão de impressão é o CMYK (do inglês Cyan - azul, Magenta - magenta ou fúcsia, Yellow - amarelo e K - Key, a cor usada como chave para o alinhamento das demais, o preto). O olho humano distingue mais tonalidades de cor do que os sistemas de cor reproduzem, sendo que o sistema RGB atinge maior variedade de tons do que o CMYK. Essa diferença de padrões ocorre porque a formação de um determinado tom é feita a partir da adição (no sistema RGB) ou subtração (no sistema CMYK) das cores primárias em cada sistema. Com isso, a mesma coordenada de cores para ambos os sistema pode resultar em tons de cores diferentes. Os programas de desenho geralmente utilizam outro modelo de cores para padronizar o sistema utilizado no monitor e na impressora. Mas, em alguns casos, essa configuração está desabilitada, ou mesmo o sistema-padrão de cores utilizado não é o modelo que padroniza ambos os sistemas.

\section{4 - Tabelas}

As tabelas são utilizadas para se organizarem de forma concisa informações relevantes para a compreensão da ideia do trabalho. Devem estar numeradas conforme são citadas ao longo do texto, em algarismos arábicos seguidos de um ponto. Para um efeito visualmente elegante, pode-se optar por manter apenas as linhas horizontais das tabelas. Diferentemente das figuras, o título deve estar na parte superior da tabela, justificado e em espaçamento simples. Conferir, como exemplo, a Tabela 2 (traduzido de Quaglio et al. 2008) abaixo.

\section{9 - Considerações finais}

As orientações aqui apresentadas foram selecionadas pelos autores para facilitar o trabalho do estudante especificamente durante a confecção de um relatório. Alguns aspectos relacionados ao estilo poderão ser alterados conforme o estudante ganhar mais experiência na elaboração de relatórios e outros textos acadêmicos. Outros aspectos não foram aqui abordados, uma vez que estas orientações são apenas uma introdução ao tema.

Caso necessite de esclarecimento, o estudante deve buscar o professor. Isso deve ser feito desde

Tabela 2. Dimensões em mm dos exemplares representativos de Adamussium auristriatum sp. nov.

\begin{tabular}{lcccccc}
\hline Exemplar & Valva & Comprimento & Altura & Largura & Alongamento & Obesidade \\
\hline GP/1E 5301a & direita & 44 & 48 & 13 & 0,91 & 3,69 \\
\hline GP/1E 5394 & direita & 63,1 & 60,9 & 15 & 1,03 & 4,06 \\
\hline GP/1E 5457b & $\begin{array}{c}\text { direita/ } \\
\text { esquerda }\end{array}$ & 53,5 & 48,2 & 13 & 1,10 & 3,70 \\
\hline
\end{tabular}


o início e ao longo de todo o trabalho (Kearns e Gardiner 2011). O aluno nunca deve esperar que o professor se interesse pelo seu relatório. Ao contrário, o estudante deve, sempre que crer necessário, procurar o professor para resolver suas dúvidas. As questões levantadas devem ser específicas, de forma que o professor perceba que o aluno está, de fato, aprofundando-se no tema e trabalhando no relatório. Daí a importância de nunca se fazer $\mathrm{o}$ trabalho às pressas. $\mathrm{O}$ aluno interessado sempre será lembrado pelo professor no momento da avaliação. E o aluno passivo, que espera que o professor ou monitor lhe entregue todo o passo-a-passo, também.

\section{Agradecimentos}

Os autores agradecem: aos revisores A. Bartorelli e C.D.R. Carneiro pelas sugestões ao manuscrito que enriqueceram a sua versão final; à editora $\mathrm{N}$. Tudrey pelas discussões sobre o uso de termos em editoração; aos professores do IGc-USP pelas ideias gentilmente sugeridas, com base nos relatórios entregues pelos alunos em suas disciplinas: Adriana Alves, Oswaldo Siga Jr., Paulo Roberto dos Santos, Renato Paes de Almeida, Sílvio Roberto Farias Vlach e Veridiana Teixeira de Souza Martins; à aluna de graduação do IGc-USP Juliana de Freitas Rosa pelos comentários. FQ desenvolveu a maior parte deste trabalho durante seus projetos de monitoria voluntária e PAE, enquanto estudante de doutorado (bolsista CNPq) do Programa de Pós-Graduação em Geoquímica e Geotectônica do IGc-USP.

\section{0 - Referências}

Airola A., Hawkins J., Huotilainen S., Stenroos, A. 2000. How to write a report. North Karelia Polytechnic, International Business Degree Programme. URL: http://molar.crb.ucp.pt/ cursos/1\%C2\%BA\%20e\%202\%C2\%BA\%20Ciclos\%20-20Lics\%20e\%20Lics\%20com\%20Mests/MD/1\%C2\%BAANO/2\%C2\%BASEM/12UBA6/CO/3\%C2\%AA\%20aula\%20CBM/Writing\%20a\%20report.pdf. Acesso 15.05.2013.

American Psychological Association. 2009. Publication Manual of the American Psychological Association. $\left(6^{\text {th }}\right.$ ed.) Washington: APA. 272P.

Associação Brasileira de Normas Técnicas. 1989. NBR 10719: Apresentação de relatórios técnico-científicos. Rio de Janeiro: ABNT. 10p.

Associação Brasileira de Normas Técnicas. 2002. NBR 6023: Informação e documentação: referências - elabo- ração. Rio de Janeiro: ABNT. 24p.

Brazilian Journal of Geology. 2013. Diretrizes para autores. URL: http://rbg.sbgeo.org.br/index.php/rbg/ about/submissions\#authorGuidelines. Acesso: 05.07.2013.

Cintra G.U., Cretela Jr. J. 1944. Dicionário latino-português. São Paulo: Editora Anchieta Limitada. 1292p.

Gustavii B. 2003. How to Write and Illustrate a Scientific Paper. New York: Cambridge University Press. $141 \mathrm{p}$.

Jost H., Brod J.A. 2005. Como redigir e ilustrar textos em Geociências. Série Textos 1. São Paulo: Sociedade Brasileira de Geologia. 93p.

Kearns H., Gardiner M. 2011. The care and maintenance of your adviser. Nature, 469: 570.

Kretz R. 1983. Symbols for rock-forming minerals. American Mineralogist, 68: 277-279.

Monteiro G.V. 1998. Sumário ou índice? Conceitos, definições e controvérsias. Acta Cirurgica Brasileira, 13(2). URL: http://www. scielo.br/scielo.php?script = sci_arttext\&pid =S0102-86501998000200011. Acesso 20.03.2014.

Moraes R. 2007. O Plágio na Pesquisa Acadêmica: a proliferação da desonestidade intelectual. Revista Diálogos Possíveis, 6 (2). URL: www.fsba.edu. br/dialogospossiveis/artigos/4/06.pdf. Acesso 18.03.2014.

Oliveira E.B.P.M., Sígolo J.B. 2005. Orientação para elaboração de teses, dissertações e outros trabalhos acadêmicos. Geologia USP: Série Didática, 3(1): 1-56.

Paiva R.B. 2010. Proposta de Adoção de medidas para prevenção do plágio nas Instituições de Ensino e do comércio ilegal de monografias. Proposição 2010.19.0737901, Relator: J.R.L. Campelo. Ementa número 34/2010/COP. Conselho Federal da Ordem dos Advogados do Brasil.

Quaglio F., Anelli L.E., Santos P.R., Perinotto J.A.J., Rocha-Campos A.C. 2008. Invertebrates from the Low Head Member (Polonez Cove Formation, Oligocene) at Vauréal Peak, King George Island, West Antarctica. Antarctic Science, 20: 149-168.

Rodrigues, S.W.O., Archanjo, C.J., Grohmann, C.H. 2010. Quantificação da deformação finita nos metagranitoides Cariris Velhos na região de Alagoa Grande (PB). Geologia USP, Série Científica 10 (3): 57-58.

Severino A.J. 2007. Metodologia do trabalho científico. $23^{\mathrm{a}}$. ed. rev. e atual. São Paulo: Cortez. 304p.

Silva O.S.F. 2007. Entre o plágio e a autoria: qual o papel da universidade? Revista Brasileira de Educação, 13 (38): 357-414.

Vasconcelos, S.M.R. 2007. O plágio na comunidade científica: questões culturais e linguísticas. Ciência e Cultura, 59(3): 4-5. 